\title{
MicroRNA-34b expression enhances chemosensitivity of endometrial cancer cells to paclitaxel
}

\author{
MEGUMI YANOKURA*, KOUJI BANNO* and DAISUKE AOKI \\ Department of Obstetrics and Gynecology, Keio University School of Medicine, Tokyo 160-8582, Japan
}

Received June 28, 2019; Accepted July 23, 2020

DOI: 10.3892/ijo.2020.5127

\begin{abstract}
Aberrant DNA methylation is widely observed in various types of cancer, and expression of microRNAs (miRNAs/miRs) is suppressed by DNA methylation. The present study explored tumor suppressor miRNAs downregulated by DNA methylation in endometrial cancer cells, as the basis of a novel therapeutic approach for endometrial cancer. Among 821 candidate miRNAs, miR-34b was identified as an upregulated miRNA after demethylation treatment in all four endometrial cancer cell lines (HEC-108, SNG-II, Ishikawa and HHUA) examined. miR-34b expression with or without demethylation treatment in cancer cells was confirmed by TaqMan quantitative PCR. MYC and MET, the predicted target genes of miR-34b, were downregulated at both the RNA and protein levels following miR-34b overexpression. Following miR-34b treatment, inhibition of cell growth and invasion, and cell cycle arrest were observed in HEC-108 cells. Sensitivity to paclitaxel was increased in cancer cells with miR-34b overexpression, compared with untreated cancer cells, but this difference was not identified for cisplatin or doxorubicin. In vivo, combination treatment with miR-34b and paclitaxel markedly reduced tumor growth compared with treatment with negative control miRNA and paclitaxel. These data suggest that miR-34b enhances paclitaxel sensitivity in endometrial cancer cells, and that miR-34b and MET are key targets for treatment of endometrial cancer. The present results may contribute to the development of combination treatment with a demethylation agent, miR-34b mimic or MET inhibitor and an anticancer drug.
\end{abstract}

Correspondence to: Dr Kouji Banno, Department of Obstetrics and Gynecology, Keio University School of Medicine, 35 Shinanomachi, Shinjuku-ku, Tokyo 160-8582, Japan

E-mail:kbanno@keio.jp

*Contributed equally

Abbreviations: miRNA, microRNA; nega-miR, negative control miRNA; 5-aza, 5-Aza-2'-deoxycytidine; DAB, 3,3'-diaminobenzidine

Key words: endometrial cancer, microRNA, microRNA-34b, chemosensitivity, paclitaxel

\section{Introduction}

MicroRNAs (miRNAs/miRs) are a class of non-coding RNAs that are 18 to 25 nucleotides in length $(1,2)$. These molecules can regulate the expression of hundreds of target genes, and serve important regulatory roles in fundamental biological processes, including cell proliferation, differentiation and apoptosis via negative regulation of gene expression (3-5). Consistent with their roles in these processes, a number of studies have identified widespread alteration of miRNA expression in cancer (6-8). miRNAs may function as tumor suppressors or oncogenes, and dysregulation of miRNA expression is associated with tumorigenesis, cancer progression and metastasis.

In endometrial cancer, changes in miRNAs may influence cancer proliferation and differentiation (9-12). Several studies have investigated aberrant miR-34 family expression and its roles in cancer (13-17). The three members of the human miR-34 family (miR-34a, miR-34b and miR-34c) induce cell cycle arrest and apoptosis, and are downregulated in cancer $(14,15,18)$. Therefore, these molecules are tumor suppressor miRNAs. Downregulation of miR-34 family expression may occur for several reasons, including genetic mutation and aberrant DNA methylation of the promoter region (19-22). Our previous studies have demonstrated widespread aberrant DNA methylation in both endometrial cancer tissue and cells (23-26). Therefore, identification of epigenetically silenced miRNA and exploration of dysregulation of miRNA and its functions in endometrial cancer may be beneficial for diagnosis or therapy. Indeed, miR-34 replacement therapy is currently undergoing clinical trials for primary liver cancer (27). However, little is known regarding the association between endometrial cancer and miR-34 family dysregulation.

The present study investigated epigenetically silenced tumor suppressor miRNAs in endometrial cancer cells, and identified miR-34b as one such miRNA. Subsequently, miR-34b function and effects on chemosensitivity of these cells were explored. Downregulation of $M E T$ expression by miR-34b overexpression enhanced the chemosensitivity of endometrial cancer cells to paclitaxel. The present findings may contribute to development of epigenetic medicine or individualized therapy for endometrial cancer.

\section{Materials and methods}

Cell lines and culture. Six human endometrial cancer cell lines were used in the present study: SNG-II and HHUA 
cells were established at Keio University (Tokyo, Japan), Ishikawa cells were established at National Kasumigaura Hospital (Ibaraki, Japan), HEC108 and HEC1B cells were purchased from the Health Science Research Resources Bank, and the KLE cell line was purchased from American Type Culture Collection. KLE was maintained in DMEM/F12 (Sigma-Aldrich; Merck KGaA) supplemented with 10\% FBS. (Gibco; Thermo Fisher Scientific, Inc.) and 1\% penicillin/streptomycin (Gibco; Thermo Fisher Scientific, Inc.) at $37^{\circ} \mathrm{C}$ in a $5 \% \mathrm{CO}_{2}$ humidified incubator. All other cells were maintained in Ham's F12 medium (Sigma-Aldrich; Merck KGaA) supplemented with $10 \% \mathrm{FBS}$ and $1 \%$ penicillin/streptomycin at $37^{\circ} \mathrm{C}$ in a $5 \% \mathrm{CO}_{2}$ humidified incubator.

Demethylation treatment. Endometrial cancer cells were plated on a $10-\mathrm{cm}$ dish at a density of $10^{6}$ cells/dish and cultured at $37^{\circ} \mathrm{C}$ with $5 \% \mathrm{CO}_{2}$ for $72 \mathrm{~h}$. Subsequently, 5-Aza-2'-deoxycytidine (5-aza; Sigma-Aldrich; Merck KGaA), a demethylating agent, was added at a final concentration of $1 \mu \mathrm{M}$ in culture medium. After $48 \mathrm{~h}$ of incubation at $37^{\circ} \mathrm{C}$ with $5 \% \mathrm{CO}_{2}, 1 \mu \mathrm{M} 5$-aza was added again and RNA was extracted $72 \mathrm{~h}$ after the second addition of 5-aza.

DNA, RNA and protein extraction. An AllPrep DNA/RNA/miRNA Universal kit (Qiagen $\mathrm{GmbH}$ ) was used to extract DNA, RNA and miRNA from all samples according to the manufacturer's protocol. For protein extraction, cells were lysed using a Mammalian Cell Extraction kit (BioVision, Inc.) according to the manufacturer's protocol.

miRNA microarrays and data analysis. Total RNA (100 ng) was labeled with cyanine 3-pCp (Cy3) fluorescent dye using a miRNA Labeling Reagent and Hybridization kit (Agilent Technologies, Inc.). Cy3-labeled RNA from each sample was hybridized to an Agilent Human miRNA Version 2 Microarray (Agilent Technologies, Inc.). The hybridized array was washed and scanned according to the manufacturer's protocols. Data were extracted from scanned images using Feature Extraction v.10.1.1.1 (Agilent Technologies, Inc.) and the results were analyzed using GeneSpring GX 10 software (Agilent Technologies, Inc.). Raw data were normalized and 798 miRNAs were used in further analysis. Differentially expressed miRNAs in each cell line with or without 5-aza treatment were identified using fold-change analysis. A Venn diagram was used to show common altered miRNAs in the four analyzed cell lines.

Reverse transcription and TaqMan quantitative PCR (qPCR) validation. cDNA was reverse transcribed at $42^{\circ} \mathrm{C}$ for $15 \mathrm{~min}$ from each total RNA sample using a TaqMan Advanced miRNA cDNA synthesis kit (Applied Biosystems; Thermo Fisher Scientific, Inc.). Prefabricated TaqMan MicroRNA assays (containing miRNA-specific forward and reverse PCR primers and a miRNA-specific Taqman MGB probe; Applied Biosystems; Thermo Fisher Scientific, Inc.) were used to determine the expression levels of miR-34b (AB Assay ID, 002102, miRBase accession no. MIMAT0004676). The PCR conditions were as follows: Initial denaturation at $95^{\circ} \mathrm{C}$ for $5 \mathrm{~min}$, followed by 14 cycles of $95^{\circ} \mathrm{C}$ for $3 \mathrm{sec}$ and $60^{\circ} \mathrm{C}$ for $30 \mathrm{sec}$, and final extension at $99^{\circ} \mathrm{C}$ for $10 \mathrm{~min}$. Reverse transcription (RT)-qPCR was performed using TaqMan Fast Advanced Master Mix in a QuantStudio 5 (Thermo Fisher Scientific, Inc.). miR-34b expression was calculated using the $\Delta \Delta \mathrm{Cq}$ method (28) using miR-423-5p (AB Assay ID, 002340; miRBase accession no. MIMAT0004748) as an internal control.

miRNA transfection. Cells were plated on a $6-\mathrm{cm}$ dish at a density of $2 \times 10^{5}$ cells/dish at $24 \mathrm{~h}$ before transfection. miR-34b (5'-CAAUCACUAACUCCACUGCCAU-3'; 5 nM; Assay ID; PM12727; Applied Biosystems; Thermo Fisher Scientific, Inc.) or Pre-miR miRNA Precursor negative control miRNA \#1 (cat. no. AM17110; 5 nM; Applied Biosystems; Thermo Fisher Scientific, Inc.) was then transfected using siPORT NeoFX transfection agent (Applied Biosystems; Thermo Fisher Scientific, Inc.). The medium was changed every 2 days after transfection. After $48 \mathrm{~h}$ of miRNA transfection, miR-34b and target gene expression levels were analyzed by RT-qPCR. After $192 \mathrm{~h}$ of miRNA transfection, MET and MYC protein levels were analyzed by western blotting.

Expression analysis of target genes. cDNA for GAPDH, $M E T$ and $M Y C$ expression analysis was synthesized at $42^{\circ} \mathrm{C}$ for 50 min using a SuperScript First-Strand Synthesis System for RT-PCR kit (Invitrogen; Thermo Fisher Scientific, Inc.) from $1 \mu \mathrm{g}$ total RNA. PowerUp SYBR-Green Master Mix (Applied Biosystems; Thermo Fisher Scientific, Inc.) was used for RT-qPCR, with $10 \mu \mathrm{l}$ PCR reaction mixture containing 1X qPCR mix, $0.25 \mu \mathrm{M}$ primers and $0.5 \mu 1$ synthesized 1st strand cDNA as template. The primers used for RT-qPCR were as follows: GAPDH forward, 5'-GAAGGTGAAGGT CGGAGTC-3' and reverse, 5'-GAAGATGGTGATGGGATT TC-3'; $M E T$ forward, 5'-TGAAATTCATCCAACCAAATC TT-3' and reverse, 5'-AATAGAAAACTGACAATGTTGAGA GG-3'; and MYC forward, 5'-CTGGGAAGGGAGATCCGG AGC-3' and reverse, 5'-GGGGCATCGTCGCGGGAGGCT G-3'. The PCR conditions were as follows: $50^{\circ} \mathrm{C}$ for $2 \mathrm{~min}$, $95^{\circ} \mathrm{C}$ for $15 \mathrm{sec}$, followed by 40 cycles of $95^{\circ} \mathrm{C}$ for $15 \mathrm{sec}$ and $60^{\circ} \mathrm{C}$ for $60 \mathrm{sec}$. Quantification was performed using the QuantStudio 5 (Thermo Fisher Scientific, Inc.). Expression levels of $M E T$ and $M Y C$ were calculated using the $\triangle \Delta \mathrm{Cq}$ method (28) with GAPDH as an internal control. The present study used TargetScan 6.2 (http://www.targetscan.org) for target prediction of miR-34b.

Western blot analysis. Total protein concentration was determined using the UV absorption method (GeneQuant 100; GE Healthcare). A total of $50 \mu \mathrm{g}$ protein was electrophoresed on a $10 \%$ polyacrylamide gel and proteins were transferred to nitrocellulose membranes (Bio-Rad Laboratories, Inc.). The membranes were soaked in PBS containing 1\% BSA (Sigma-Aldrich; Merck KGaA) and 0.1\% Tween-20, and incubated at room temperature for $1 \mathrm{~h}$ for blocking. Subsequently, they were incubated with anti- $\beta$-actin antibody (AC-74; cat. no. A2228; dilution, 1:5,000; Sigma-Aldrich; Merck KGaA), anti- $\beta$-tubulin antibody (TU-20; can. no. CBL412; dilution, 1:100; Chemicon International; Thermo Fisher Scientific, Inc.), anti-MET antibody (H-10; cat. no. sc-514149; dilution, 1:200; Santa Cruz Biotechnology, Inc.) and anti-MYC antibody (c-19; cat. no. sc-788; dilution, 1:200; Santa Cruz Biotechnology, Inc.) 
at $4^{\circ} \mathrm{C}$ overnight, followed by three washes with PBS containing $0.1 \%$ Tween (PBS-T). The samples were incubated with biotinylated anti-mouse IgG antibody (cat. no. BA-2000; dilution, 1:200; Vector Laboratories, Inc.) at room temperature for $1 \mathrm{~h}$. The membranes were rinsed with PBS-T three times and incubated with ATP binding cassette transporters (ABC) complex at room temperature for $1 \mathrm{~h}$. Membranes were rinsed with PBS-T twice and PBS once, and signals were visualized with 3,3'-diaminobenzidine (DAB; Sigma-Aldrich; Merck KGaA).

Colony formation assay and cell cycle analysis. Cells were plated at a density of $1 \times 10^{4}$ cells/10-cm dish. At 7 days after miRNA transfection, colonies were stained with $0.1 \%$ crystal violet in $50 \%$ methanol at room temperature for $20 \mathrm{~min}$ and imaged with an inverted phase contrast microscope in a colony formation assay. The number of colonies was quantified using ImageJ software (Ver. 1.4.6; National Institutes of Health). For cell cycle analysis, $1 \times 10^{7}$ cells were fixed in $70 \%$ cold ethanol at $4^{\circ} \mathrm{C}$ for $30 \mathrm{~min}$, RNase-treated, stained with propidium iodide (Sigma-Aldrich; Merck KGaA) at room temperature for $15 \mathrm{~min}$ in the dark, and analyzed within $1 \mathrm{~h}$. The cell cycle profile was determined using a Gallios flow cytometer (Beckman Coulter, Inc.). Cell cycle analysis was performed with Kaluza software (version 1.1; Beckman Coulter, Inc.).

Transwell migration and invasion assays. Migration and invasion assays were performed 7 days after transfection of miRNAs. Cell culture insert 24-well plates with an $8-\mu \mathrm{m}$ pore size and BD BioCoat Matrigel invasion chambers (BD Biosciences) were used for migration and invasion assays. In the respective assays, $1 \times 10^{5}$ and $2 \times 10^{5}$ cells/well were plated in the upper Transwell insert in $0.5 \mathrm{ml}$ serum-free F12 medium (Sigma-Aldrich; Merck KGaA). The lower compartment contained 0.75 ml F12 medium with 10\% FCS (Gibco; Thermo Fisher Scientific, Inc.). Cells were incubated at $37^{\circ} \mathrm{C}$ in a $5 \% \mathrm{CO}_{2}$ incubator for $30 \mathrm{~h}$. Cells in the upper Transwell chamber were carefully removed with a cotton swab. Cells that migrated or invaded to the lower surface of the membrane were fixed and stained using a Diff-Quik kit (Sysmex Corporation) according to the manufacturer's protocol. Migrating and invading cells were counted under a light microscope (magnification, x200; CX21; Olympus Corporation) in five randomly selected microscope fields.

In vitro chemosensitivity analysis. After $48 \mathrm{~h}$ of miRNA transfection, endometrial cancer cells were plated on 96-well plates at $5.0 \times 10^{4}$ cells/well and cultured for $48 \mathrm{~h}$. These cells were treated with various concentrations of paclitaxel $\left(1.0 \times 10^{-5}\right.$, $0.5 \times 10^{-5}$ and $\left.1.0 \times 10^{-6} \mathrm{M}\right)$, cisplatin $\left(1.0 \times 10^{-4}, 0.5 \times 10^{-4}\right.$ and $\left.1.0 \times 10^{-5} \mathrm{M}\right)$ or doxorubicin $\left(1.0 \times 10^{-5}, 0.5 \times 10^{-5}\right.$ and $\left.1.0 \times 10^{-6} \mathrm{M}\right)$ with or without miR-34b transfection. Viable cells were quantified $48 \mathrm{~h}$ after administration of anticancer drugs using a Cell Counting Kit-8 (Dojindo Molecular Technologies, Inc.) according to the manufacturer's protocol. Cytotoxicity was measured by determining the $\mathrm{IC}_{50}$ of each anticancer drug in terms of cell growth compared with the control.

In vivo experiments. The care and use of animals in the present study were approved by the Animal Research Center at Keio University (Tokyo, Japan). A total of 15 BALB/c nude mice housed at $20-25^{\circ} \mathrm{C}$ with $30-60 \%$ humidity under a $12: 12 \mathrm{~h}$ light/dark cycle with ad libitum access to food and water were used for the xenograft experiment. HEC1B cells $\left(1 \times 10^{7}\right)$ in $100 \mu \mathrm{l}$ PBS were subcutaneously injected at two sites in the flank of 15 female 6-week-old nude mice (weight, 18-22 g) obtained from CLEA Japan, Inc. After 14 days, mice with tumor formation were randomly divided into five groups [negative control miRNA (nega-miR), miR-34b, paclitaxel, nega-miR and paclitaxel, and miR-34b and paclitaxel]. Paclitaxel was administered intraperitoneally at $20 \mathrm{mg} / \mathrm{kg}$ and a mixture of miRNA and atelocollagen (Koken Co., Ltd.) was injected at the tumor site on alternate days. Tumor diameters were measured every week and the tumor volume $\left(\mathrm{mm}^{3}\right)$ was calculated as follows: $V=$ length $\mathrm{x}$ width $^{2} \mathrm{x} 1 / 2$. Five tumors were used in each group. The mice were euthanized at 28 days post-injection using $\mathrm{CO}_{2}$ inhalation (10-30\%/min).

Immunohistochemical staining. Each extracted xenograft tumor was fixed in $4 \%$ paraformaldehyde at room temperature for $30 \mathrm{~min}$ and embedded in paraffin blocks. Tissue blocks were cut into 3- $\mu \mathrm{m}$ slices, deparaffinized in xylene, rehydrated with graded alcohols (100, 90, 70 and 50\%). Subsequently, the sections were autoclaved at $121^{\circ} \mathrm{C}$ for 10 min with sodium citrate buffer (0.01 M,pH 7.0) for antigen retrieval. Following a blocking step at room temperature for 30 min using a Vectastain Elite ABC kit (Vector Laboratories, Inc.), the sections were immunostained with anti-MET (EP1454Y; cat. no. ab51067; dilution, 1:100; Abcam), anti-MYC (Y69; cat. no. ab32072; dilution, 1:20; Abcam), anti-procaspase-3 (E61; cat. no. ab32150; dilution, 1:50; Abcam), anti-cleaved caspase-3 (cat. no. ab2302; dilution, 1:25; Abcam), anti-cleaved poly(ADP-ribose) polymerase 1 (PARP; E51; cat. no. ab32064; dilution, 1:100; Abcam) and anti-Ki67 (MIB-1; cat. no. M724001-2; dilution, 1:100; Dako; Agilent Technologies, Inc.) at $4^{\circ} \mathrm{C}$ overnight. Indirect immunohistochemical staining was performed by the avidin-biotin-peroxidase complex method using a Vectastain Elite ABC kit (Vector Laboratories, Inc.) according to the manufacturer's protocol, and visualized with DAB (Sigma-Aldrich; Merck KGaA). Sections were counterstained with hematoxylin at room temperature for $10 \mathrm{sec}$, dehydrated in a graded series of ethanol, dried and a cover slip was applied. For measurement of the proliferative index, staining data were captured under a light microscope (magnification, x200; CX21; Olympus Corporation) randomly in five areas per slide. Ki67-positive cells and cancer cells were counted and the Ki67 index was calculated as Ki67-positive cells/cancer cells.

Statistical analysis. Each experiment was performed at least three times and data are presented as the mean \pm SD. Statcel3 statistical software (OMS Ltd.) was used for analysis. Comparisons between two groups were performed by Mann-Whitney U test. Comparisons among three or more groups were conducted using one-way ANOVA with a Tukey post hoc test or Kruskal-Wallis and a Steel-Dwass post hoc test. $\mathrm{P}<0.05$ was considered to indicate a statistically significant difference.

\section{Results}

miRNAs upregulated by demethylation treatment. To identify tumor suppressor miRNAs that are epigenetically silenced 
A

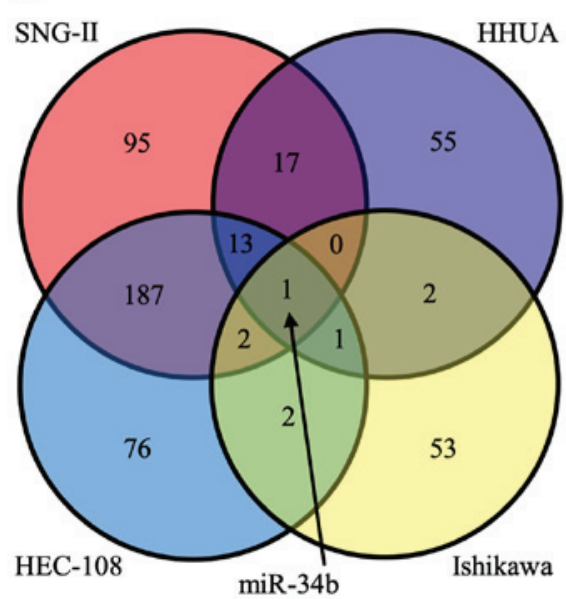

B

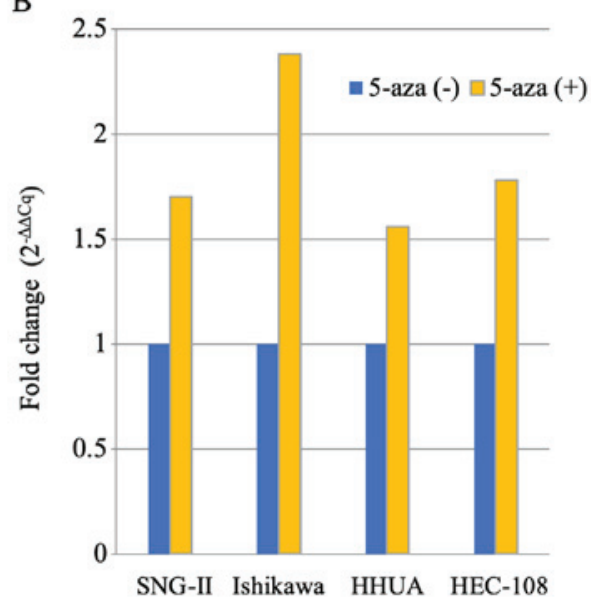

Figure 1. Upregulated miR expression following demethylation treatment. (A) Venn diagram of upregulated miRs after demethylation treatment (120 h) in four endometrial cancer cell lines. Numbers in overlapping areas show the number of upregulated miRNAs in two, three or four comparison pairs. Only miR-34b was upregulated in all four endometrial cancer cell lines. (B) miR-34b expression in the four cell lines analyzed by reverse transcription-quantitative PCR. The yellow bars show the fold change of expression following demethylation treatment $(120 \mathrm{~h})$ compared with control (blue bar) in each cell line. 5-aza, 5-Aza-2'-deoxycytidine; miR, microRNA.

by DNA methylation and to investigate the function of these miRNAs in endometrial cancer, differentially expressed miRNAs were analyzed using a microarray before and after demethylation treatment in three well-differentiated endometrial cancer cell lines (SNG-II, HHUA and Ishikawa) and one poorly-differentiated endometrial cancer cell line (HEC-108). Among 821 miRNAs, only miR-34b was upregulated (fold change $>1.5$ ) in all four cell lines (Fig. 1A). miR-34b upregulation after demethylation treatment was confirmed by Taqman qPCR. In all four cell lines, miR-34b expression was increased 1.56-2.38 fold compared with the level before treatment (Fig. 1B). This result suggests that miR-34b is commonly suppressed in endometrial cancer cells and may serve an important role in endometrial cancer progression or chemosensitivity.

Expression levels of miR-34b target genes in endometrial cancer cells. Identification of target genes of miR-34b is important for understanding the functions and molecular mechanisms of miR-34b. Binding of miRNAs to the 3 -untranslated region (UTR) is the basis of most target site prediction algorithms. The present study used TargetScan 6.2 for target prediction of miR-34b, and identified MET and MYC as the predicted target genes. Although no statistically significant difference was demonstrated, after increased miR-34b expression following miR-34b transfection was demonstrated (Fig. 2A), target gene expression was analyzed. The expression levels of MET and MYC were downregulated in HEC-108, HEC-1B and KLE cells after miR-34b transfection at the RNA and protein levels with no statistically significant differences observed (Fig. 2B-F). This demonstrated that MET and MYC may be targets of miR-34b.

Cell growth following miR-34b treatment. Further analysis was performed to investigate the effect of miR-34b via its target genes. To examine the effect of miR-34b via MYC in cell proliferation and the cell cycle in endometrial cancer cells, a colony formation assay and flow cytometry analysis were performed. The number of colonies was significantly reduced 7 days after miR-34b treatment compared with the nega-miR treatment group (Fig. 3). In flow cytometry, The proportion of $G_{0} / G_{1}$ phase cells was increased in miR-34b-treated cells compared with the others (Fig. 4). Subsequently, it was investigated whether miR-34b affects cell invasion and motility, since $M E T$ is associated with cell migration and invasion in lung cancer cells (1). In Transwell assays, significantly reduced migration, but not invasion, was observed after miR-34b treatment compared with treatment with nega-miR in HEC-108 cells (Figs. 5 and 6).

Effect of miR-34b on chemosensitivity in vitro. To investigate the effect of miR-34b on chemosensitivity in endometrial cancer cells, a MTT assay with miR-34b treatment was performed in HEC-108, HEC-1B and KLE cells. These cell lines were used since our previous studies demonstrated that they exhibit chemoresistance under normal conditions (24-26). There was little change in chemosensitivity to cisplatin and doxorubicin in HEC-108, HEC-1B and KLE cell lines with and without miR-34b overexpression at the concentrations examined (Fig. 7). However, paclitaxel sensitivity was enhanced by miR-34b transfection in all three cell lines (Fig. 7). Treatment with miR-34b changed the $\mathrm{IC}_{50}$ for paclitaxel from $0.9 \times 10^{-5}$ to $0.8 \times 10^{-5}$ in HEC- 108 cells, from $0.3 \times 10^{-5}$ to $1.0 \times 10^{-6}$ in HEC-1B cells and from $0.4 \times 10^{-5}$ to $1.0 \times 10^{-6}$ in KLE cells (Table I).

Effect of miR-34b on chemosensitivity in vivo. To investigate whether miR-34b has an effect on chemosensitivity in endometrial cancer in vivo, as well as in vitro, a xenograft tumor model was established. After 4 weeks of treatment, tumor growth was significantly suppressed in the paclitaxel + miR-34b group compared with in the paclitaxel + nega-miR group (Fig. 8). After measuring the tumor diameter, all xenograft tumors were removed and paraffin-embedded sections were prepared. MET and MYC protein levels were examined by immunohistochemistry. Following miR-34b treatment, both MET and $M Y C$ expression were suppressed, indicating that miR-34b has 

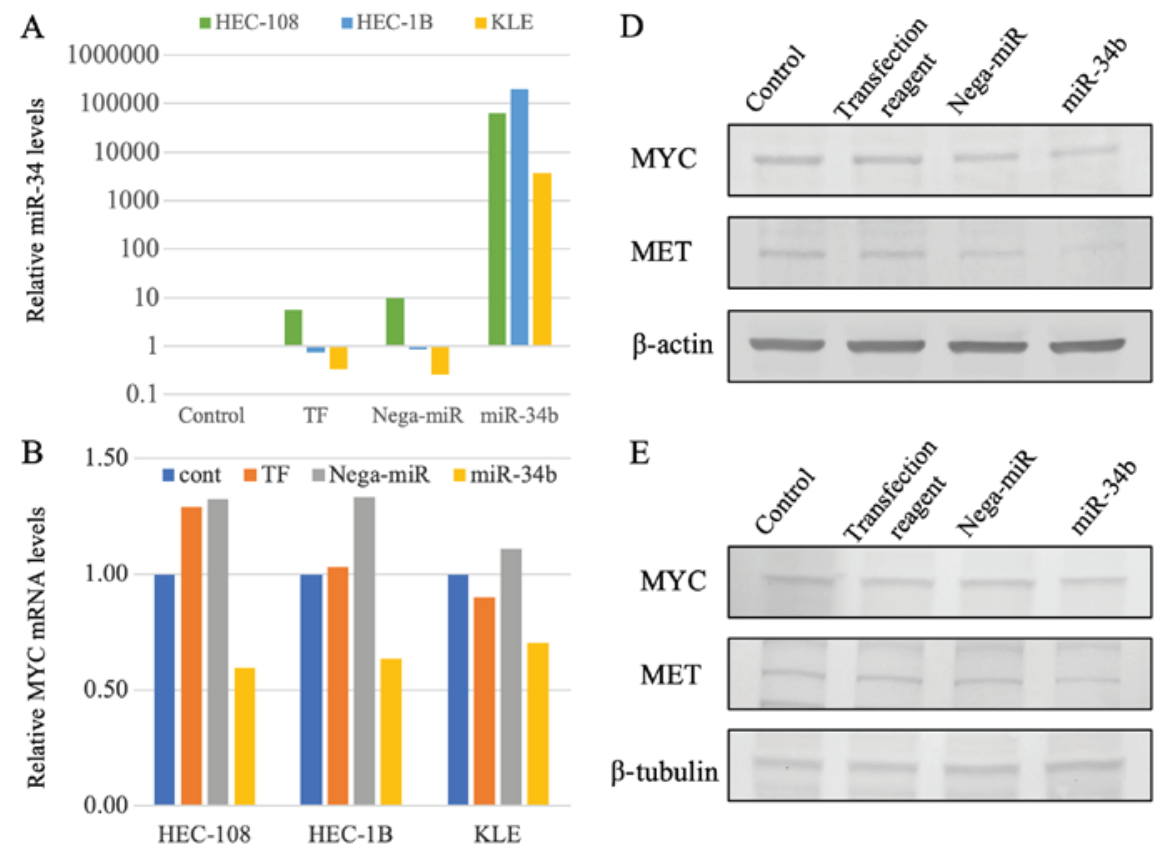

$\mathrm{E}$
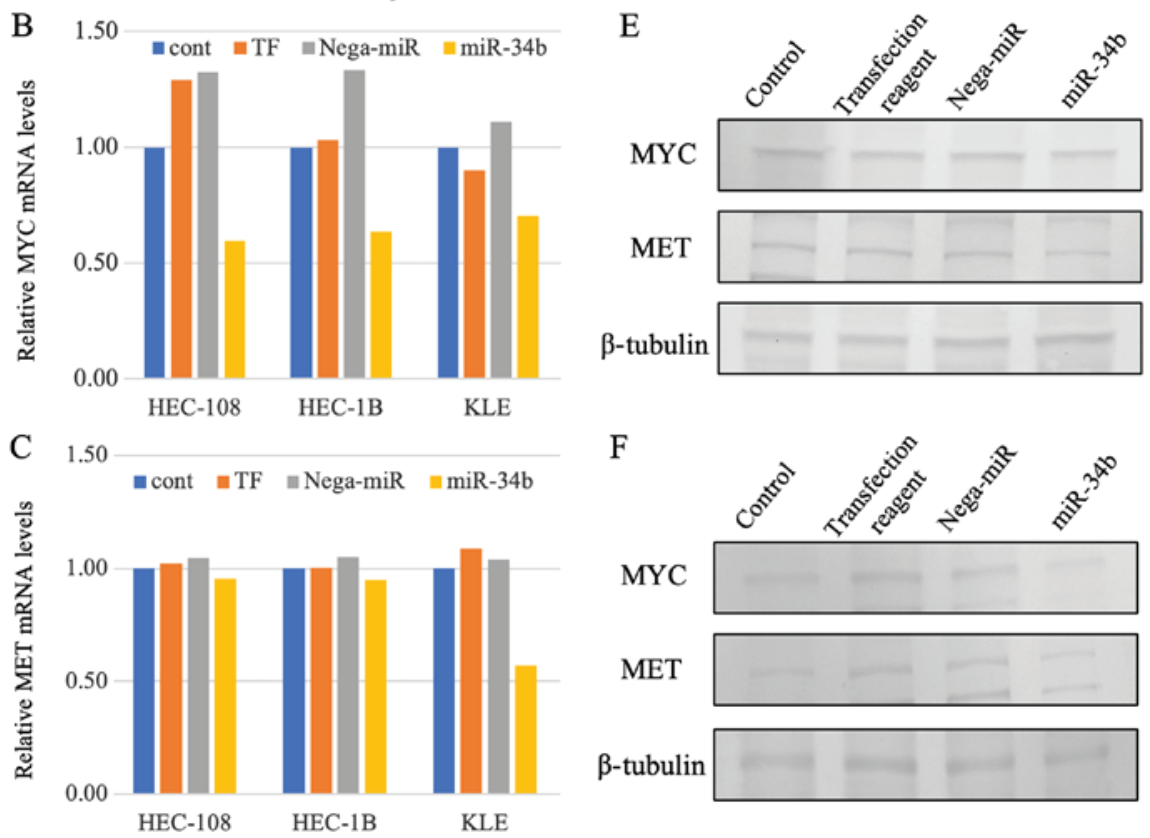

Figure 2. miR-34b and target gene expression. (A) miR-34b expression assessed by RT-qPCR. After $48 \mathrm{~h}$ of miR-34b transfection, miR-34b expression was markedly upregulated compared with that in HEC-108, HEC-1B and KLE cell lines. (B) MYC gene expression assessed by RT-qPCR. After $48 \mathrm{~h}$ of miR-34b transfection, MYC expression was reduced by 54.9, 52.1 and 36.5\% compared with that in HEC-108, HEC-1B and KLE cells transfected with nega-miR, respectively. (C) MET gene expression assessed by RT-qPCR. After $48 \mathrm{~h}$ of miR-34b transfection, MET expression was reduced by 8.7, 9.4 and $45.1 \%$ compared with that in HEC-108, HEC-1B and KLE cells transfected with nega-miR, respectively. (D-F) MET and MYC protein expression was assessed by western blotting. MET and MYC protein expression was reduced after $192 \mathrm{~h}$ of miR-34b transfection in (D) HEC-108, (B) HEC-1B and (F) KLE cells. $\beta$-actin or $\beta$-tubulin was used as the internal control. cont, Control; miR-34b, microRNA-34b; nega-miR, negative control microRNA; RT-qPCR, reverse transcription-quantitative PCR; TF, transfection reagent.
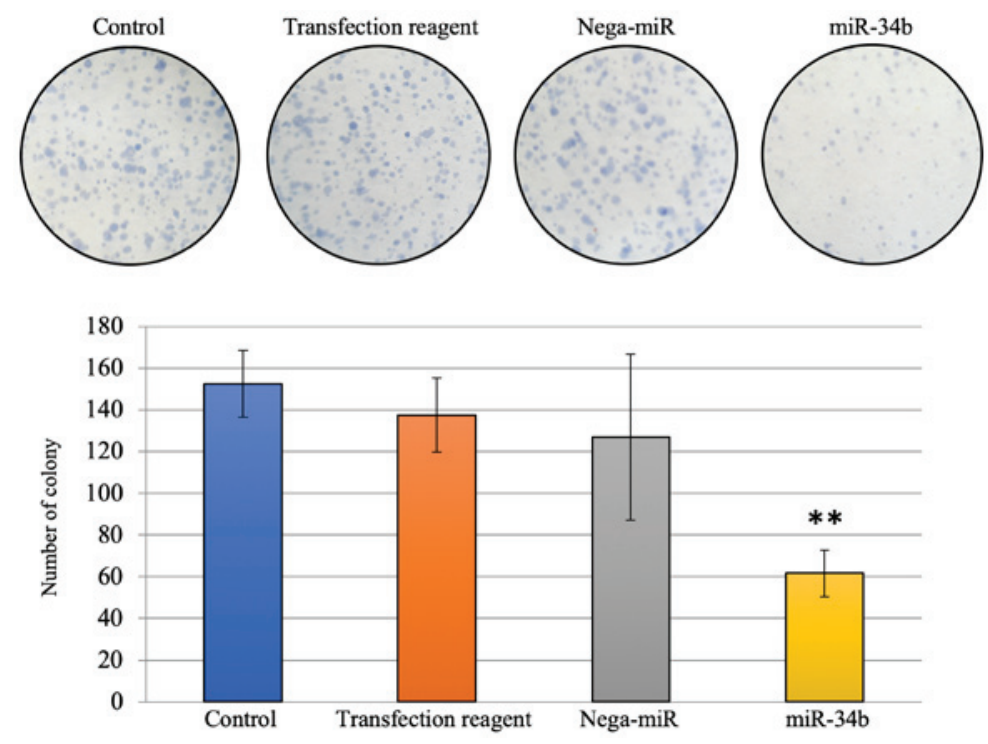

Figure 3. Cell proliferation following miR-34b treatment. Growth of HEC-108 cells was assessed using a colony formation assay. Representative images (top) and average colony numbers (bottom) are shown. Images were captured in five random areas for each group. Data are presented as the mean \pm SD. miR-34b treatment significantly inhibited the proliferation of HEC- 108 cells compared with nega-miR treatment. ${ }^{* *} \mathrm{P}<0.01$ vs. nega-miR (one-way ANOVA with Tukey's post hoc test). Original magnification, x200. miR-34b, microRNA-34b; nega-miR, negative control microRNA. 

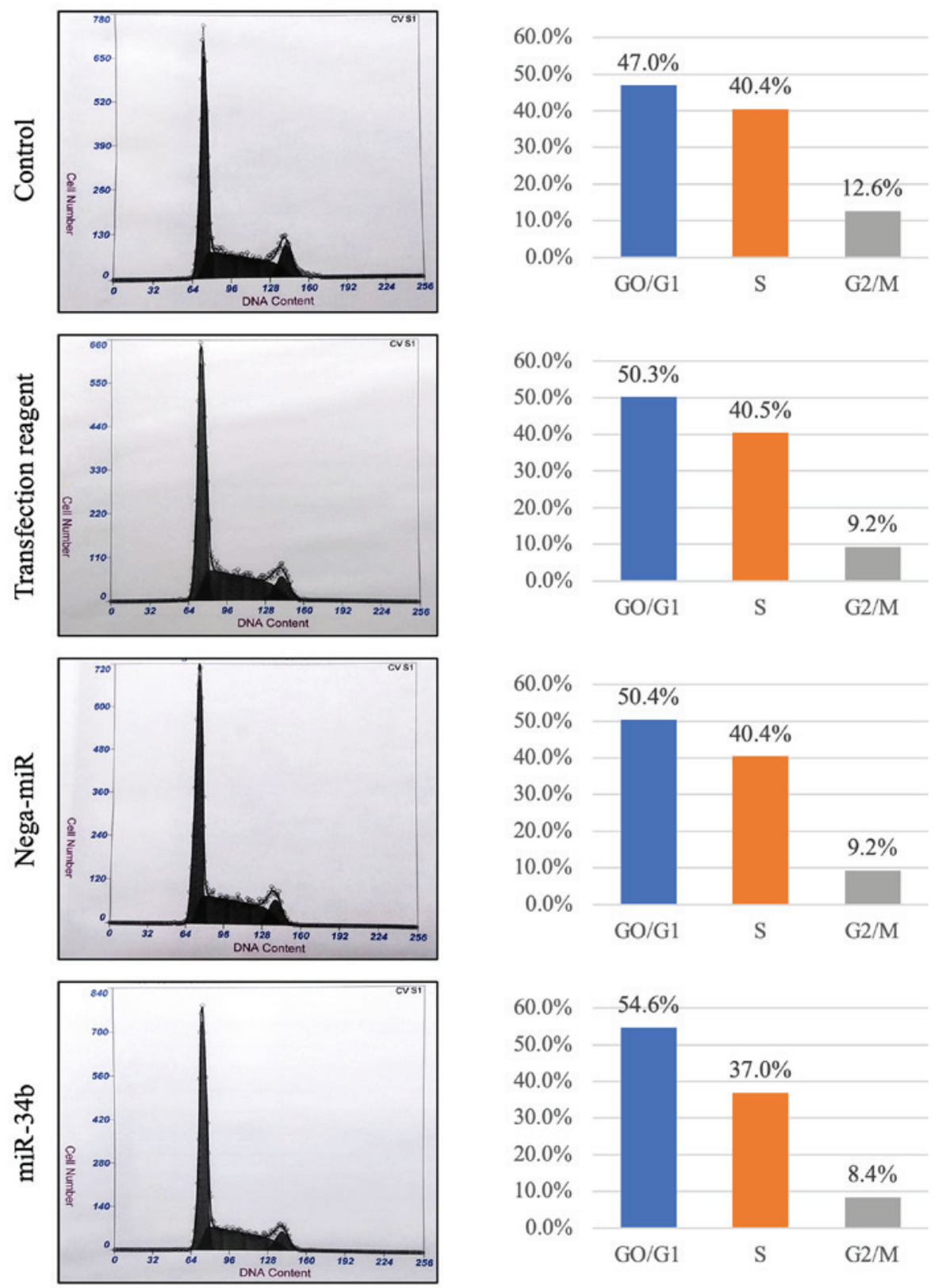

Figure 4. Cell cycle analysis of HEC-108 cells using flow cytometry. A total of $1 \times 10^{5}$ cells were used for the analysis. Cell cycle distribution images at $120 \mathrm{~h}$ after miR-34b transfection are shown on the left. The percentage of cells in each stage of the cell cycle is summarized on the right. miR-34b, microRNA-34b; nega-miR, negative control microRNA.

an effect on these genes in vivo as well as in vitro (Fig. 9). Subsequently, it was examined whether miR-34b affects cell growth and apoptosis in vivo using immunohistochemical staining of Ki67, caspase-3 and PARP. Tumor growth was suppressed in the paclitaxel + miR-34b treatment group compared with the paclitaxel + nega-miR treatment group; however, no significant difference was observed for Ki67 staining (Fig. 10A). Pro caspase-3, cleaved caspase-3 and PARP staining was positive after treatment with paclitaxel + miR-34b, but not after treatment with paclitaxel + nega-miR (Fig. 10B). Caspase- 3 serves a central role in the execution of cancer cell apoptosis and is responsible for cleavage of PARP during cell death (29). Cleavage of caspase-3 and PARP to its active form is considered to be an important event in cancer cell apoptosis. Therefore, these results demonstrated that paclitaxel + miR-34b combination treatment induces apoptosis.

\section{Discussion}

Aberrant DNA methylation of promoter regions is widely observed in human cancer and results in suppression of the expression of genes and miRNA $(7,8)$. In our previous studies, it was demonstrated that genes silenced by DNA methylation serve important roles in the progression and chemosensitivity of endometrial cancer (23-26). MiR-34b, one of the tumor suppressor miRNA is downregulated in cancer by aberrant DNA methylation (19-22). MET and MYC, the predicted target genes of miR-34b, serve important roles in cancer progression and metastasis, including in migration, invasion, cell proliferation and cell cycle progression (18,30-34).

The results of the present study demonstrated that miR-34b expression was downregulated in four endometrial cancer cells following DNA methylation. Restoration of miR-34b reduced 

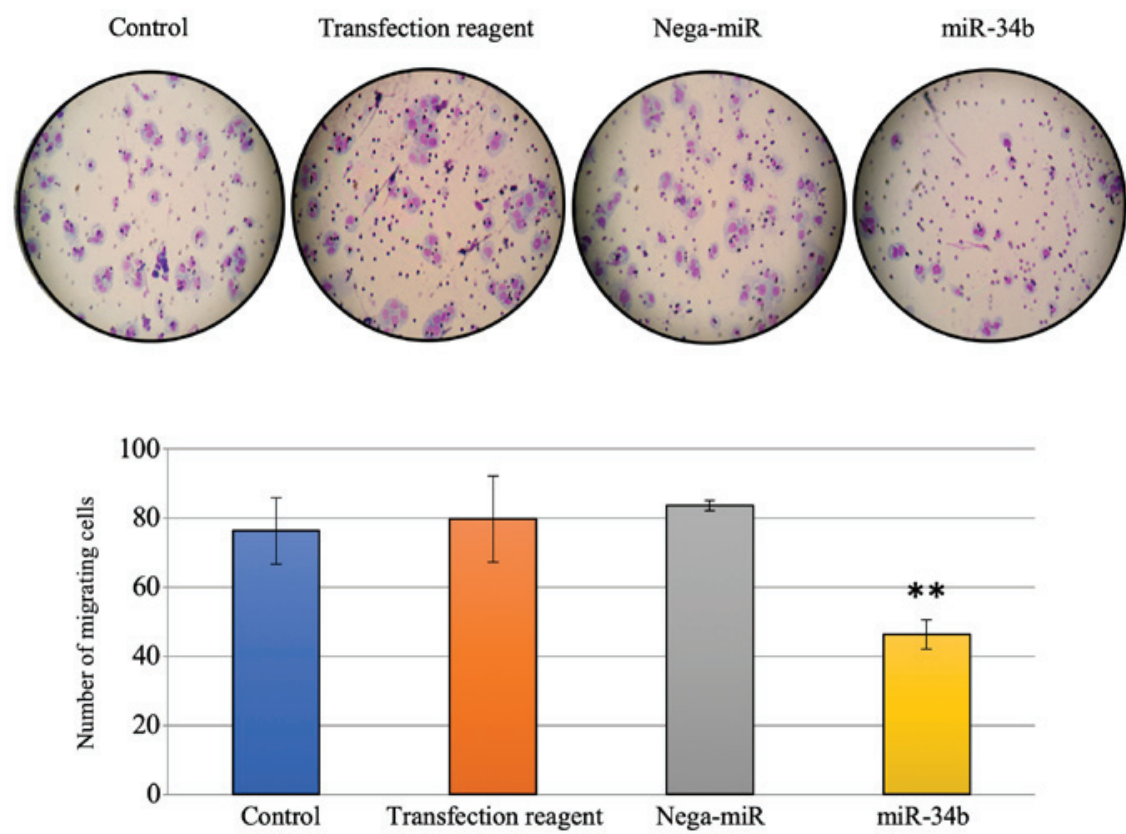

Figure 5. Migration of HEC-108 cells following miR-34b transfection. Representative images of migrating cells were captured after $30 \mathrm{~h}$ using a Transwell assay (top) in three random areas for each group. Each bar in the bottom graph represents the mean \pm SD. The number of migratory cells was significantly decreased in the miR-34b treatment group compared with the nega-miR group. ${ }^{* *} \mathrm{P}<0.01$ vs. nega-miR (one-way ANOVA with Tukey's post hoc test). Original magnification, x200. miR-34b, microRNA-34b; nega-miR, negative control microRNA.
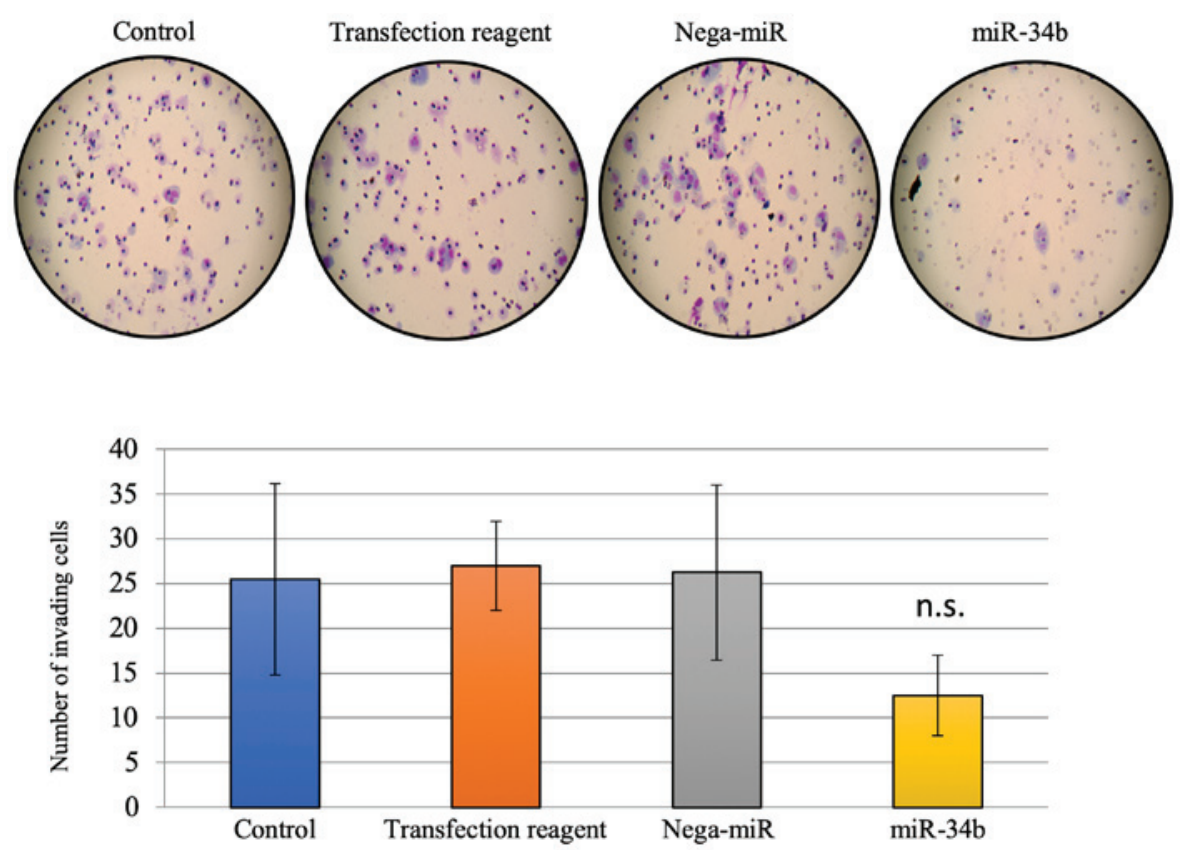

Figure 6. Invasion of HEC-108 cells following miR-34b transfection. Representative images of invading cells were captured after $30 \mathrm{~h}$ using a Transwell assay (top) in three random areas for each group. Each bar in the bottom graph represents the mean \pm SD. No significant difference was observed in the number of invading cells in the miR-34b treatment group compared with the other groups. Original magnification, x200. miR-34b, microRNA-34b; nega-miR, negative control microRNA; n.s., not significant.

cell growth, invasion and migration, and increased cell cycle arrest. Several reports have demonstrated that the 3'-UTR of MYC contains a binding site for miR-34b, and transient miR-34b expression decreases the expression of endogenous MYC $(31,32,35)$. Increased MYC expression induces growth and proliferation and strongly sensitizes cells toward proapoptotic stimuli, including DNA damaging agents $(35,36)$. Consequently, downregulation of $M Y C$ is required to ensure cell cycle arrest and survival of cells in response to DNA damage $(35,36)$. Similarly, the ability to downregulate $M Y C$ in the presence of strong mitogenic signals is required for oncogene-induced senescence, and may therefore constitute a tumor-suppressive mechanism (37). $\mathrm{G}_{1}$ arrest and reduced cell growth in endometrial cancer cells were observed in the present study, which may have been induced by downregulation of $M Y C$ expression due to miR-34b transfection. 
Table $\mathrm{I}_{\mathrm{IC}} \mathrm{IC}_{50}(\mathrm{M})$ of anticancer drugs for inhibition of growth of endometrial cancer cells with or without miR-34b treatment.

\begin{tabular}{|c|c|c|c|c|c|c|}
\hline \multirow{2}{*}{$\begin{array}{l}\text { Treatment } \\
\text { Doxorubicin, M }\end{array}$} & \multicolumn{2}{|c|}{ HEC-108 cells } & \multicolumn{2}{|c|}{ HEC-1B cells } & \multicolumn{2}{|c|}{ KLE cells } \\
\hline & $0.3 \times 10^{-5}$ & $0.2 \times 10^{-5}$ & $0.7 \times 10^{-5}$ & $0.6 \times 10^{-5}$ & $0.5 \times 10^{-5}$ & $0.6 \times 10^{-5}$ \\
\hline Cisplatin, M & $0.4 \times 10^{-4}$ & $0.3 \times 10^{-4}$ & $0.4 \times 10^{-5}$ & $0.4 \times 10^{-5}$ & $0.3 \times 10^{-4}$ & $0.3 \times 10^{-4}$ \\
\hline Paclitaxel, M & $0.9 \times 10^{-5}$ & $0.8 \times 10^{-5}$ & $0.3 \times 10^{-5}$ & $1.0 \times 10^{-6}$ & $0.4 \times 10^{-5}$ & $1.0 \times 10^{-6}$ \\
\hline $\operatorname{miR}-34 b$ & $(-)$ & $(+)$ & $(-)$ & $(+)$ & $(-)$ & $(+)$ \\
\hline
\end{tabular}

miR-34b, microRNA-34b.
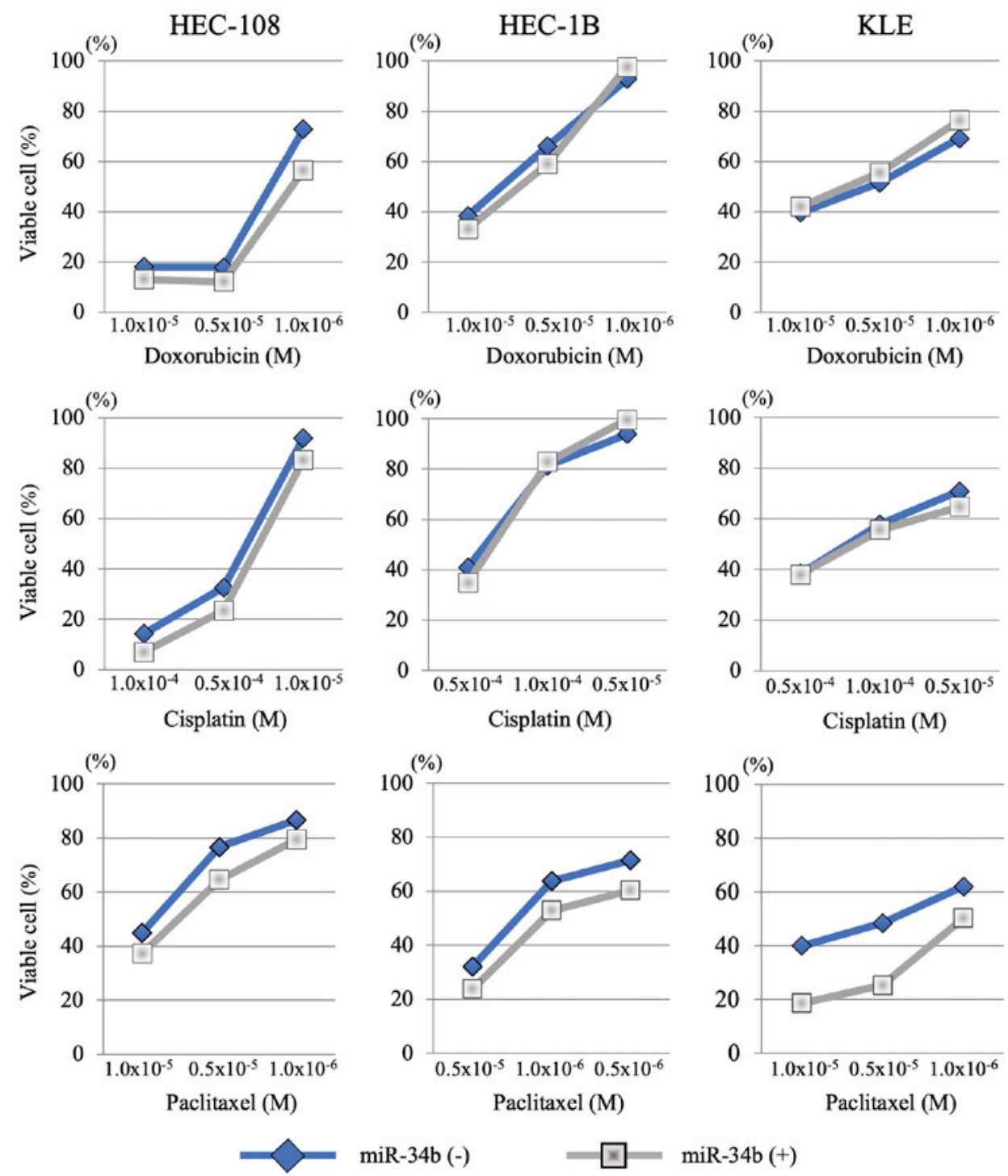

Figure 7. Chemosensitivity of endometrial cancer cell lines to anticancer drugs with or without miR-34b treatment was assessed using an MTT assay. Each graph shows the viable cell percentage after treatment of HEC-108, HEC-1B or KLE cells with doxorubicin, cisplatin or paclitaxel at the indicated concentrations. Each plot shows the average cell viability in triplicate experiments with miR-34b (gray line) or without miR-34b (blue line). miR-34b, microRNA-34b.

Furthermore, reduced cell invasion of endometrial cancer cells was observed. Previous reports have revealed that $M E T$ oncogene expression is suppressed by miR-34b overexpression in lung, colon and ovarian cancer cells $(19,30,38)$. MET small interfering RNA reduces adhesion, invasion, metastasis and tumor burden in a cancer xenograft model, and miR-34b downregulation is associated with metastasis in human cancers $(30,39)$. The present results suggest that the miR-34b-MET signaling pathway may serve an important role in invasion and migration of endometrial cancer cells, as has been demonstrated in other types of cancer.

MET is associated with chemosensitivity of cancer cells, with recent studies revealing that inhibition of MET expression increases paclitaxel sensitivity and chemotherapy-induced 


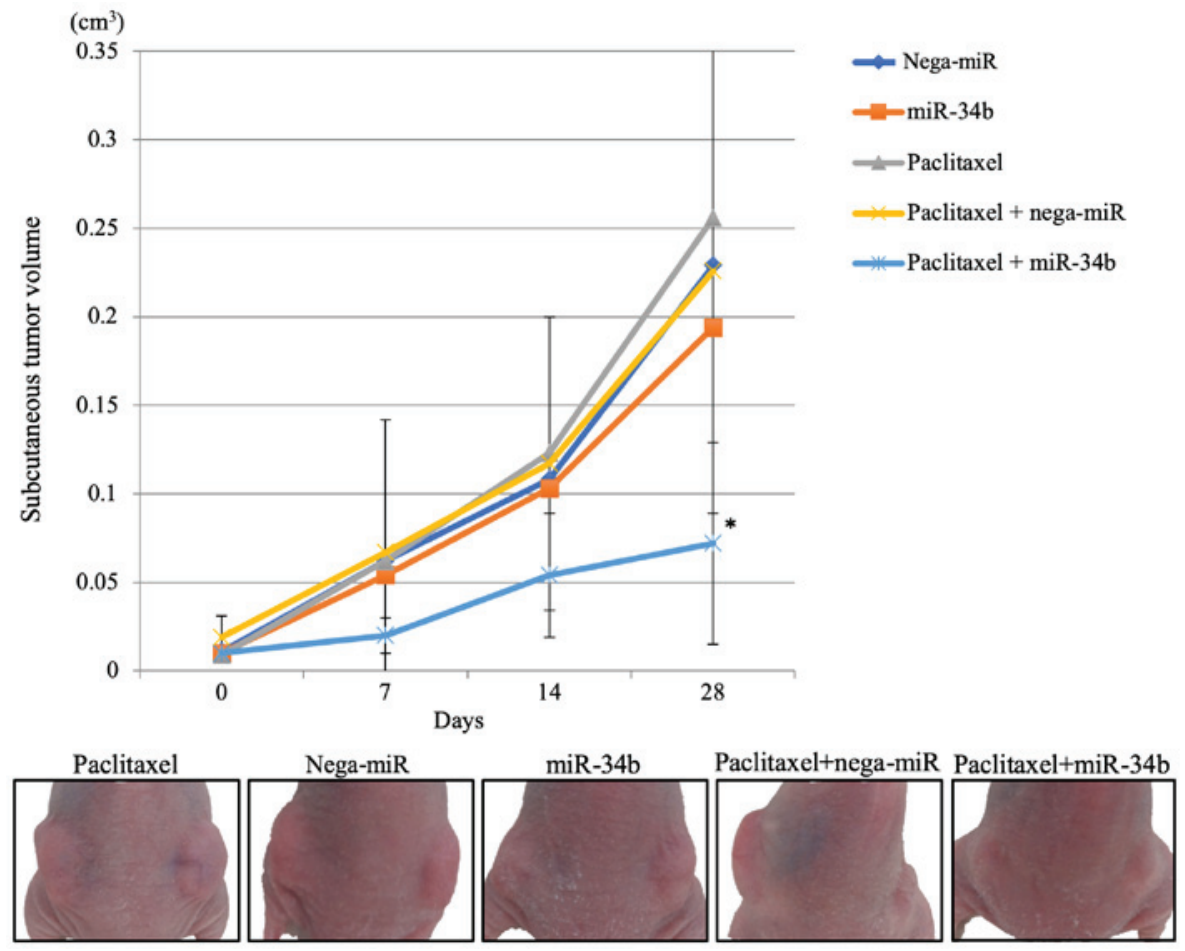

Figure 8. Effect of miR-34b on paclitaxel treatment in vivo. Average tumor volume over time is shown on the top panel (day 0 is the first day of treatment). Each plot shows the average xenograft tumor volume ( $\mathrm{n}=5$ in each group). After treatment for 28 days, the tumor volume in the paclitaxel + miR-34b group was significantly reduced compared with that in the paclitaxel + nega-miR group. ${ }^{*} \mathrm{P}<0.05$ vs. paclitaxel + nega-miR (Kruskal-Wallis test with a Steel-Dwass post hoc test). Representative images of nude mice are shown on the bottom panel. miR-34b, microRNA-34b; nega-miR, negative control microRNA.
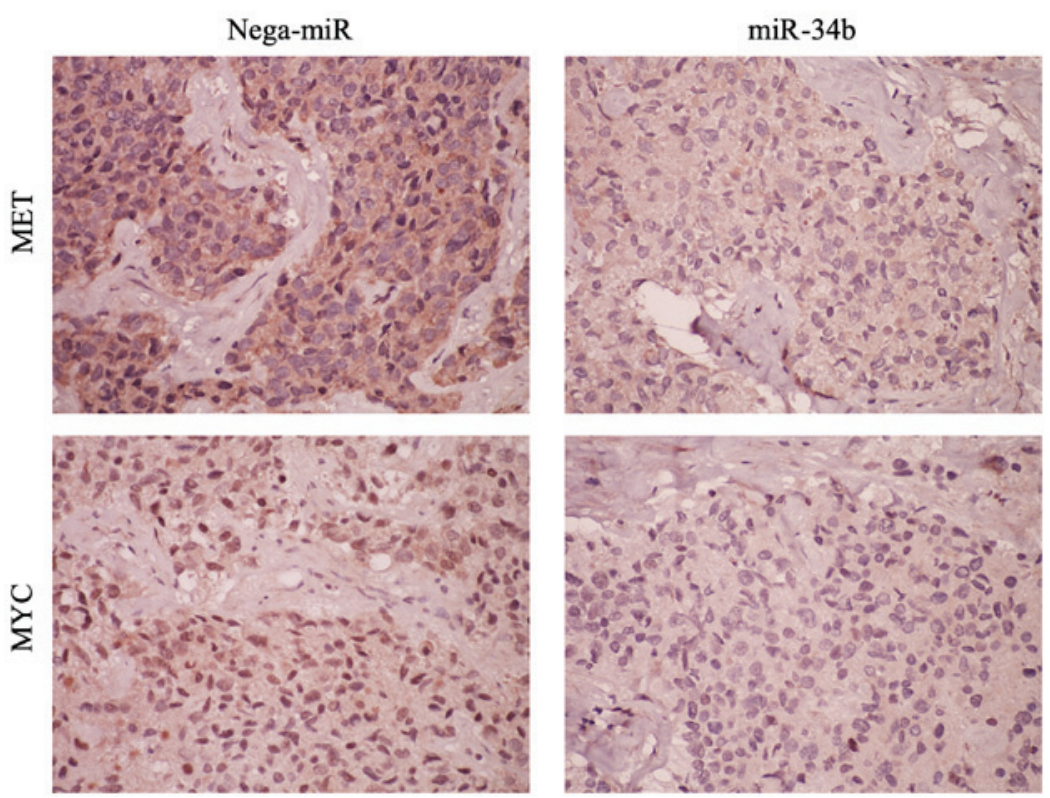

Figure 9. Immunohistochemistry of MET and MYC protein in xenograft tumor tissues. Magnification, x200. Staining images were captured for all xenograft tumors in each group, and representative images are shown. MET and MYC staining were both weaker after miR-34b transfection compared with those after transfection of nega-miR. miR-34b, microRNA-34b; nega-miR, negative control microRNA.

apoptosis $(33,34)$. An effect of a MET inhibitor and paclitaxel combination treatment has been identified in ovariancancercells and glioma cells $(33,39)$. This combination treatment results in inhibition of cell growth and widespread death of cancer cells. It was concluded that reduced expression of MET could block progression to $S$ phase and DNA synthesis, and could abrogate $\mathrm{G}_{2} / \mathrm{M}$ phase arrest in cancer cells by chemotherapy. MET gene downregulation via miR-34b overexpression may have caused a similar chemosensitivity change to paclitaxel in endometrial cancer cells in the present study. Therefore, the present results are consistent with previous reports $(33,39)$. Cells are most sensitive to chemotherapy during the $\mathrm{G}_{2} / \mathrm{M}$ phase, and less sensitive in $G_{1}$ and $S$ phases (40). In a previous study, it has been demonstrated that after exposure to chemotherapy, 
A

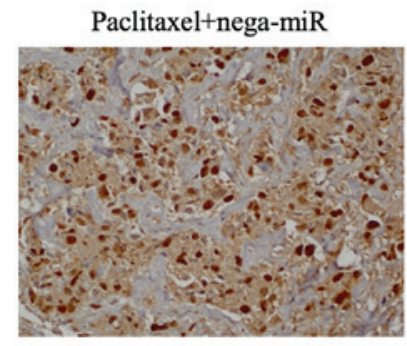

Paclitaxel+miR-34b

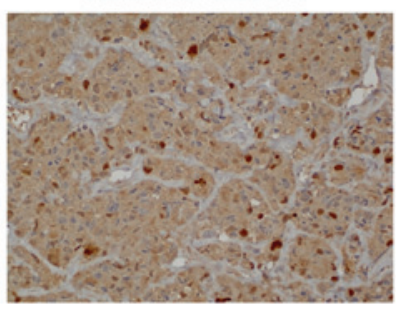

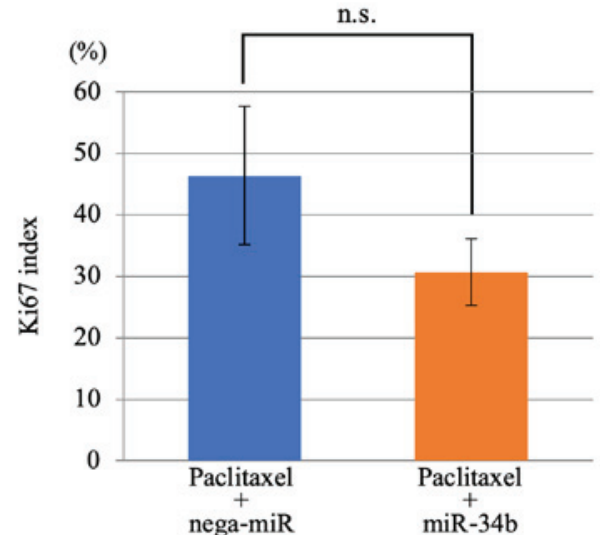

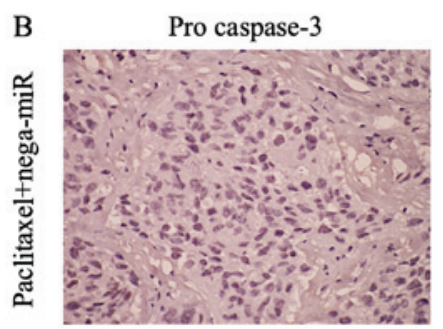

Cleaved caspase-3

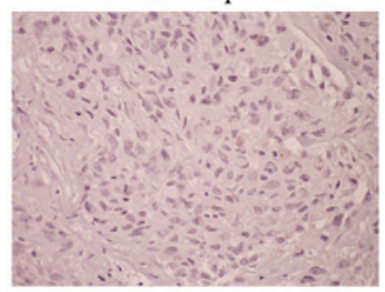

Cleaved PARP
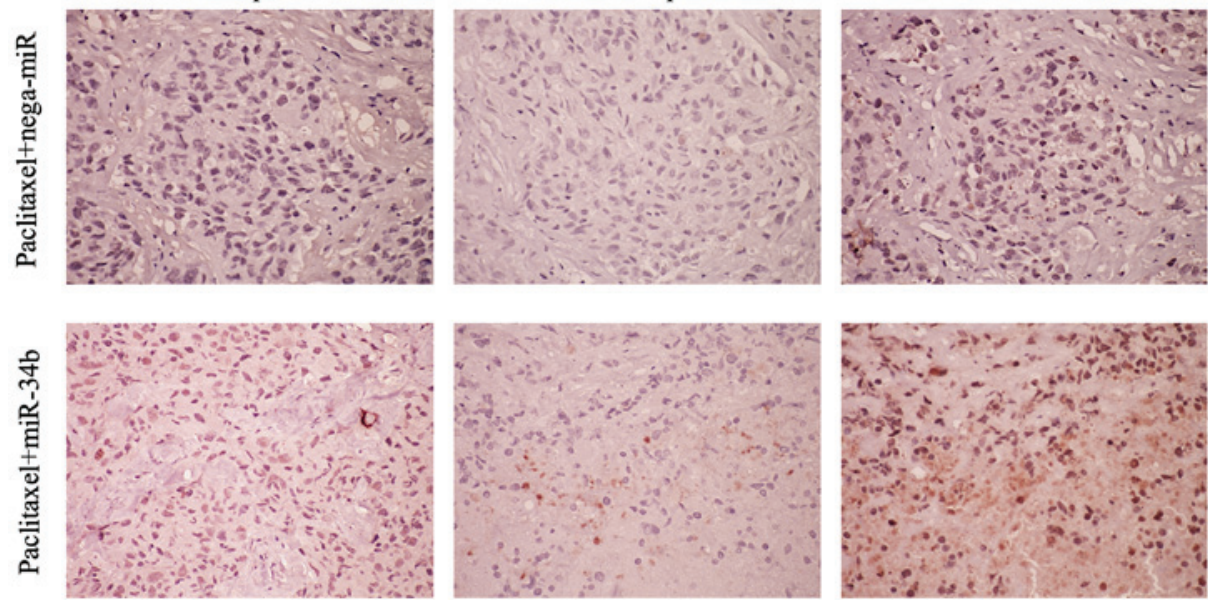

Figure 10. Decreased proliferative index and increased apoptosis following paclitaxel + miR-34b combination treatment. (A) Ki67 staining of xenograft tumors. Proliferative indexes in the paclitaxel + nega-miR and paclitaxel + miR-34b groups and representative images from each group are shown. Original magnification, $x 200$. In each group, staining images were captured in five random areas, and positively stained cells were counted in all areas. Each bar in the graph represents the mean \pm SD. The significance of differences between groups (paclitaxel + nega-miR vs. paclitaxel + miR-34b) was assessed using a Mann-Whitney U test. (B) Detection of apoptosis-related proteins in xenograft tumors. Few tumor cells in the paclitaxel + nega-miR group exhibited positive staining for pro caspase-3, cleaved caspase-3 and cleaved PARP, whereas tumor cells in the paclitaxel + miR-34b group exhibited weak positive procaspase-3 staining, and positive staining for cleaved caspase-3 and cleaved PARP, indicating that apoptosis was increased. Original magnification, x200. miR-34b, microRNA-34b; nega-miR, negative control microRNA; n.s., not significant; PARP, poly(ADP-ribose) polymerase 1.

$\mathrm{G}_{2} / \mathrm{M}$ phase arrest is the main protective effect that allows cells to repair DNA damage, maintain genetic stability of their daughter cells, and avoid mutations in cellular DNA (40). Drugs or agents that abrogate $\mathrm{G}_{2} / \mathrm{M}$ arrest after chemotherapy will increase chemosensitivity, as illustrated by abrogation of the $\mathrm{G}_{2} / \mathrm{M}$ checkpoint and chemosensitization of ovarian cancer cells following treatment with a MET inhibitor (33). The present results demonstrated that miR-34b overexpression induces $G_{1}$ phase arrest and decreases cell numbers in $S$ phase in endometrial cancer cells, and this redistribution of the cell cycle may establish a chemosensitive state. This may explain why only chemosensitivity to paclitaxel was increased, but not that to cisplatin and doxorubicin, since paclitaxel affects cells in the $\mathrm{G}_{2} / \mathrm{M}$ phase (41).

Furthermore, it was revealed that miR-34b overexpression enhanced paclitaxel sensitivity in endometrial cancer cells in vivo, as well as in vitro. Following paclitaxel + miR-34b combination treatment, induction of apoptosis was observed compared with paclitaxel + nega-miR treatment. Therefore, MET downregulation via overexpression of miR-34b may increase the sensitivity to treatment with paclitaxel as a single agent.

Suppression of miR-34b and increased $M E T$ expression were identified in endometrial cancer tissues compared with normal endometrium tissues (data not shown), although the sample size was small. Therefore, aberrant miR-34b suppression may occur in endometrial cancer cells and tissues. Numerous targeted inhibitors of MET have been developed, and clinical trials of the efficiency of these inhibitors for solid tumor treatment are being conducted (42-44). The MET gene is a key target for cancer therapy, and the present data support these studies.

In summary, the present study identified miR-34b as an upregulated miRNA from among 821 candidate miRNAs after demethylation treatment in four endometrial cancer cell lines. Inhibition of cell growth, invasion, migration 
and cell cycle arrest were observed following miR-34b overexpression, and increased sensitivity to paclitaxel was reported in vitro and in vivo. The present study only included preliminary data for miR-34b and MET expression in endometrial cancer tissues, and a large scale analysis is required. However, the present results may contribute to the development of endometrial cancer treatment with a MET inhibitor, miR-34 mimic or a demethylation agent in combination with an anticancer drug.

\section{Acknowledgements}

The authors would like to thank Professor Shiro Nozawa and Dr Isamu Ishiwata (Keio University, Tokyo, Japan) for providing SNG-II and HHUA cells, and Dr Masato Nishida (National Kasumigaura Hospital, Ibaraki, Japan) for providing Ishikawa cells.

\section{Funding}

The present study was supported by grants from JSPS KAKENHI Grants-in-Aid for Scientific Research (C) (grant nos. 15K10727 and 16K11154; to MY and KB).

\section{Availability of data and materials}

The datasets used and/or analyzed during the current study are available from the corresponding author on reasonable request.

\section{Authors' contributions}

KB designed the experiments, and analyzed and interpreted the data. MY performed the experiments and analyzed the data. DA contributed to statistical analysis and interpretation of the data. All authors drafted, reviewed and edited the manuscript, and all authors agree to be accountable for all aspects of the research in ensuring that the accuracy or integrity of any part of the work are appropriately investigated and resolved. All authors read and approved the final manuscript.

\section{Ethics approval and consent to participate}

Animal protocols were in compliance with the Guide for the Care and Use of Laboratory Animals at Keio University of School of Medicine. All experiments were approved by the Ethics Committee of Keio University School of Medicine.

\section{Patient consent for publication}

Not applicable.

\section{Competing interests}

The authors declare that they have no competing interests.

\section{References}

1. Lee JM, Yoo JK, Yoo H, Jung HY, Lee DR, Jeong HC, Oh SH, Chung HM and Kim JK: The novel miR-7515 decreases the proliferation and migration of human lung cancer cells by targeting c-Met. Mol Cancer Res 11: 43-53, 2013.
2. Kozloski GA, Jiang X, Bhatt S, Ruiz J, Vega F, Shaknovich R, Melnick A and Lossos IS: miR-181a negatively regulates NF- $\kappa B$ signaling and affects activated B-cell-like diffuse large B-cell lymphoma pathogenesis. Blood 127: 2856-2866, 2016.

3. Ivey KN and Srivastava D: MicroRNAs as regulators of differentiation and cell fate decisions. Cell Stem Cell 7: 36-41, 2010.

4. Bueno MJ and Malumbres M: MicroRNAs and the cell cycle. Biochim Biophys Acta 1812: 592-601, 2011.

5. Su Z, Yang Z, Xu Y, Chen Y and Yu Q: MicroRNAs in apoptosis, autophagy and necroptosis. Oncotarget 6: 8474-8490, 2015.

6. Rachagani S, Macha MA, Menning MS, Dey P, Pai P, Smith LM, Mo YY and Batra SK: Changes in microRNA (miRNA) expression during pancreatic cancer development and progression in a genetically engineered KrasG12D;Pdx1-Cre mouse (KC) model. Oncotarget 6: 40295-40309, 2015.

7. Balacescu O, Sur D, Cainap C, Visan S, Cruceriu D, Manzat-Saplacan R, Muresan MS, Balacescu L, Lisencu C and Irimie A: The Impact of miRNA in colorectal cancer progression and its liver metastases. Int J Mol Sci 19: 3711, 2018.

8. Mavrogiannis AV, Kokkinopoulou I, Kontos CK and Sideris DC: Effect of vinca alkaloids on the expression levels of microRNAs targeting apoptosis-related genes in breast cancer cell lines. Curr Pharm Biotechnol 19: 1076-1086, 2018.

9. Bao W, Zhang Y, Li S, Fan Q, Qiu M, Wang Y, Li Y, Ji X, Yang Y, Sang Z, et al: miR 1075 p promotes tumor proliferation and invasion by targeting estrogen receptoralpha in endometrial carcinoma. Oncol Rep 41: 1575-1585, 2019.

10. Li L, Shou H, Wang Q and Liu S: Investigation of the potential theranostic role of $\mathrm{KDM} 5 \mathrm{~B} / \mathrm{miR}-29 \mathrm{c}$ signaling axis in paclitaxel resistant endometrial carcinoma. Gene 694: 76-82, 2019.

11. Shu S, Liu X, Xu M, Gao X, Chen S, Zhang L and Li R: MicroRNA-320 acts as a tumor suppressor in endometrial carcinoma by targeting IGF-1R. Int J Mol Med 43: 1505-1512, 2019.

12. Tan A, Luo R and Ruan P: miR-495 promotes apoptosis and inhibits proliferation in endometrial cells via targeting PIK3R1. Pathol Res Pract 215: 594-599, 2019.

13. Engkvist ME, Stratford EW, Lorenz S, Meza-Zepeda LA, Myklebost O and Munthe E: Analysis of the miR-34 family functions in breast cancer reveals annotation error of miR-34b. Sci Rep 7: 9655, 2017.

14. Fang LL, Sun BF, Huang LR, Yuan HB, Zhang S, Chen J, Yu ZJ and Luo H: Potent inhibition of miR-34b on migration and invasion in metastatic prostate cancer cells by regulating the TGF- $\beta$ pathway. Int J Mol Sci 18: 2762, 2017.

15. Wang $\mathrm{Y}, \mathrm{Wu} \mathrm{Z}$ and $\mathrm{Hu} \mathrm{L}$ : The regulatory effects of metformin on the [SNAIL/miR-34]:[ZEB/miR-200] system in the epithelial-mesenchymal transition (EMT) for colorectal cancer (CRC). Eur J Pharmacol 834: 45-53, 2018.

16. Metheetrairut C, Chotigavanich C, Amornpichetkul K, Keskool P, Ongard S and Metheetrairut C: Expression levels of miR-34-family microRNAs are associated with TP53 mutation status in head and neck squamous cell carcinoma. Eur Arch Otorhinolaryngol 276: 521-533, 2019.

17. Zhang L, Wang L, Dong D, Wang Z, Ji W, Yu M,Zhang F, Niu R and Zhou Y: MiR-34b/c-5p and the neurokinin-1 receptor regulate breast cancer cell proliferation and apoptosis. Cell Prolif 52: e12527, 2019.

18. Yang L, Song X, Zhu J, Li M, Ji Y, Wu F, Chen Y, Cui X, Hu J, Wang L, et al: Tumor suppressor microRNA-34a inhibits cell migration and invasion by targeting MMP-2/MMP-9/FNDC3B in esophageal squamous cell carcinoma. Int J Oncol 51: 378-388, 2017.

19. Corney DC, Hwang CI, Matoso A, Vogt M, Flesken-Nikitin A, Godwin AK, Kamat AA, Sood AK, Ellenson LH, Hermeking H and Nikitin AY: Frequent downregulation of miR-34 family in human ovarian cancers. Clin Cancer Res 16: 1119-1128, 2010

20. Javeri A, Ghaffarpour M, Taha MF and Houshmand M: Downregulation of miR-34a in breast tumors is not associated with either p53 mutations or promoter hypermethylation while it correlates with metastasis. Med Oncol 30: 413, 2013.

21. Okada N, Lin CP, Ribeiro MC, Biton A, Lai G, He X, Bu P, Vogel H, Jablons DM, Keller AC, et al: A positive feedback between $\mathrm{p} 53$ and miR-34 miRNAs mediates tumor suppression. Genes Deve 28: 438-450, 2014.

22. Xie K, Liu J, Chen J, Dong J, Ma H, Liu Y and Hu Z: Methylation-associated silencing of microRNA-34b in hepatocellular carcinoma cancer. Gene 543: 101-107, 2014.

23. Kawaguchi M, Yanokura M, Banno K, Kobayashi Y, Kuwabara Y, Kobayashi M, Nomura H, Hirasawa A, Susumu N and Aoki D: Analysis of a correlation between the BRAF V600E mutation and abnormal DNA mismatch repair in patients with sporadic endometrial cancer. Int J Oncol 34: 1541-1547, 2009. 
24. Yanokura M, Banno K, Kawaguchi M, Hirao N, Hirasawa A Susumu N, Tsukazaki K and Aoki D: Relationship of aberrant DNA hypermethylation of CHFR with sensitivity to taxanes in endometrial cancer. Oncol Rep 17: 41-48, 2007.

25. Yanokura M, Banno K, Susumu N, Kawaguchi M, Kuwabara Y, Tsukazaki K and Aoki D: Hypermethylation in the p16 promoter region in the carcinogenesis of endometrial cancer in Japanese patients. Anticancer Res 26: 851-856, 2006.

26. Banno K, Yanokura M, Susumu N, Kawaguchi M, Hirao N, Hirasawa A, Tsukazaki K and Aoki D: Relationship of the aberrant DNA hypermethylation of cancer-related genes with carcinogenesis of endometrial cancer. Oncol Reps 16: 1189-1196, 2006.

27. Agostini M and Knight RA: miR-34: From bench to bedside. Oncotarget 5: 872-881, 2014

28. Livak KJ and Schmittgen TD: Analysis of relative gene expression data using real-time quantitative PCR and the 2(-Delta Delta C(T)) method. Methods 25: 402-408, 2001.

29. Mondal A and Bennett LL: Resveratrol enhances the efficacy of sorafenib mediated apoptosis in human breast cancer MCF7 cells through ROS, cell cycle inhibition, caspase 3 and PARP cleavage. Biomed Pharmacother 84: 1906-1914, 2016.

30. Migliore C, Petrelli A, Ghiso E, Corso S, Capparuccia L, Eramo A Comoglio PM and Giordano S: MicroRNAs impair MET-mediated invasive growth. Cancer Res 68: 10128-10136, 2008.

31. Seviour EG, Sehgal V, Lu Y, Luo Z, Moss T, Zhang F, Hill SM, Liu W, Maiti SN, Cooper L, et al: Functional proteomics identifies miRNAs to target a $\mathrm{p} 27 / \mathrm{Myc} / \mathrm{phospho-Rb}$ signature in breast and ovarian cancer. Oncogene 35: 691-701, 2016.

32. Siemens H, Jackstadt R, Hunten S, Kaller M, Menssen A, Gotz U and Hermeking H: miR-34 and SNAIL form a double-negative feedback loop to regulate epithelial-mesenchymal transitions. Cell Cycle 10: 4256-4271, 2011.

33. Wang $\mathbf{J}$ and Cheng JX: c-Met inhibition enhances chemosensitivity of human ovarian cancer cells. Clin Exp Pharmacol Physiol 44: 79-87, 2017.

34. Yang L, Song Z, Wang X, Yang W, Wang M and Liu H: Huaier extract enhances the treatment efficacy of paclitaxel in breast cancer cells via the $\mathrm{NF}-\kappa \mathrm{B} / \mathrm{I} \kappa \mathrm{B} \alpha$ pathway. Oncol Rep 38 3455-3464, 2017.

35. Kress TR, Cannell IG, Brenkman AB, Samans B, Gaestel M Roepman P, Burgering BM, Bushell M, Rosenwald A and Eilers M: The MK5/PRAK kinase and Myc form a negative feedback loop that is disrupted during colorectal tumorigenesis. Mol Cell 41: 445-457, 2011.
36. Cannell IG, Kong YW, Johnston SJ, Chen ML, Collins HM, Dobbyn HC, Elia A, Kress TR, Dickens M, Clemens MJ, et al: p38 MAPK/MK2-mediated induction of miR-34c following DNA damage prevents Myc-dependent DNA replication. Proc Natl Acad Sci USA 107: 5375-5380, 2010.

37. Hydbring P, Bahram F, Su Y, Tronnersjo S, Hogstrand K, von der Lehr N, Sharifi HR, Lilischkis R, Hein N, Wu S, et al: Phosphorylation by $\mathrm{Cdk} 2$ is required for Myc to repress Ras-induced senescence in cotransformation. Proc Natl Acad Sci USA 107: 58-63, 2010.

38. Watanabe K, Emoto N, Hamano E, Sunohara M, Kawakami M, Kage H, Kitano K, Nakajima J, Goto A, Fukayama M, et al: Genome structure-based screening identified epigenetically silenced microRNA associated with invasiveness in non-small-cell lung cancer. Int J Cancer 130: 2580-2590, 2012.

39. Chu SH, Ma YB, Feng DF, Zhang H, Qiu JH and Zhu ZA: c-Met antisense oligodeoxynucleotides increase sensitivity of human glioma cells to paclitaxel. Oncol Rep 24: 189-194, 2010

40. Begg AC, Stewart FA and Vens C: Strategies to improve radiotherapy with targeted drugs. Nat Rev Cancer 11: 239-253, 2011

41. Shah MA and Schwartz GK: Cell cycle-mediated drug resistance: An emerging concept in cancer therapy. Clin Cancer Res 7: 2168-2181, 2001.

42. Choi J, Lee HE, Kim MA, Jang BG, Lee HS and Kim WH Analysis of MET mRNA expression in gastric cancers using RNA in situ hybridization assay: Its clinical implication and comparison with immunohistochemistry and silver in situ hybridization. PLoS One 9: e111658, 2014.

43. Fu P, Du F, Yao M, Lv K and Liu Y: MicroRNA-185 inhibits proliferation by targeting c-Met in human breast cancer cells. Exp Ther Med 8: 1879-1883, 2014.

44. Rubin MA: Insights into the mechanism of organ-specific cancer metastasis. Cancer Discov 4: 1262-1264, 2014.

This work is licensed under a Creative Commons Attribution-NonCommercial-NoDerivatives 4.0 International (CC BY-NC-ND 4.0) License. 